\title{
Exergoeconomic Evaluation and Optimization of Dual Pressure Organic Rankine Cycle (ORC) for Geothermal Heat Source Utilization
}

\author{
Dodeye Igbong1, Oku Nyong1 ${ }^{*}$, James Enyia1, Benjamin Oluwadare², Mafel Obhua ${ }^{3}$ \\ ${ }^{1}$ Department of Mechanical Engineering, Cross River University of Technology, Calabar, Nigeria \\ ${ }^{2}$ Department of Mechanical Engineering, Ekiti State University, Ado Ekiti, Nigeria \\ ${ }^{3}$ Nigeria Maritime University, Okerenkok, Nigeria \\ Email: *nyong.oku@gmail.com
}

How to cite this paper: Igbong, D., Nyong, O., Enyia, J., Oluwadare, B. and Obhua, M. (2021) Exergoeconomic Evaluation and Optimization of Dual Pressure Organic Rankine Cycle (ORC) for Geothermal Heat Source Utilization. Journal of Power and Energy Engineering, 9, 19-40.

https://doi.org/10.4236/jpee.2021.99002

Received: June 16, 2021

Accepted: September 27, 2021

Published: September 30, 2021

Copyright $\odot 2021$ by author(s) and Scientific Research Publishing Inc. This work is licensed under the Creative Commons Attribution International License (CC BY 4.0).

http://creativecommons.org/licenses/by/4.0/

\begin{abstract}
In the present study, a dual-pressure organic Rankine cycle (DORC) driven by geothermal hot water for electricity production is developed, investigated and optimized from the energy, exergy and exergoeconomic viewpoint. A parametric study is conducted to determine the effect of high-stage pressure $P_{H P}$ and low-stage pressure $P_{L P}$ variation on the system thermodynamic and exergoeconomic performance. The DORC is further optimized to obtain maximum exergy efficiency optimized design (EEOD case) and minimum product cost optimized design (PCOD case). The exergy efficiency and unit cost of power produced for the optimization of EEOD case and PCOD case are $33.03 \%$ and $3.059 \mathrm{cent} / \mathrm{kWh}$, which are $0.3 \%$ and $17.4 \%$ improvement over base case, respectively. The PCOD case proved to be the best, with respect to minimum unit cost of power produced and net power output over the base case and EEOD case.
\end{abstract}

\section{Keywords}

Geothermal Water, Dual Pressure Organic Rankine Cycle, Exergoeconomic Factor, Optimization

\section{Introduction}

In recent years, the utilization of low-grade heat sources such as geothermal, biomass, solar and power and industrial process waste heat, are becoming more and more attractive as a sustainable approach towards ameliorating environmental issues, such as air pollution, acid rain, global warming and ozone layer 
depletion caused by greenhouse gas emission from fossil fuel combustion. It is also considered a potential solution to reducing the energy shortage being experienced due to the rapid growth in population and economic activities around the world. Organic Rankine cycle (ORC) is widely used and considered a promising heat-to-power conversion technology that uses lower boiling temperature working fluids, which makes it suitable, flexible and efficient for converting a wide range of heat source temperature to useful power output [1] [2] [3] [4]. It has the advantage of small plant size and modularity, easy construction and low cost of operation [4]. It also has capability for better temperature matching characteristics between working fluids and the low-grade heat source fluid, especially for advance ORC configuration, thus minimizing exergy loss in the evaporators while increasing cycle exergy efficiency [3] [5].

Geothermal energy is a low-medium grade heat source, which is attracting growing attention for power generation due to concern about environmental pollution problems from fossil fuel consumption. The advantage of geothermal energy over other renewable energy like wind and solar energies, is that its availability is all year round and, independent of time of day or seasons. The utilization of geothermal energy is increasing worldwide, in 2016 the total install generating capacity was $12.7 \mathrm{GW}$ with annual electricity generation of 80.9 terawatt-hour (TWh) in 2015, accounting for $3 \%$ global electricity production [6]. Although it represents a small percentage of electricity production worldwide, in some countries geothermal accounts for more than $10 \%$ of the national electricity generation capacity [7]. At present, electricity generation from geothermal resources uses three major type of power plants: the dry-steam plants, flash plants (single, double or triple), or binary plants, depending on the state of the fluid and its temperature [7]. For geothermal wells producing high temperature steam $\left(>235^{\circ} \mathrm{C}\right)$, dry-steam plants are used. When the steam temperature is $>180^{\circ} \mathrm{C}$ and $<235^{\circ} \mathrm{C}$, the flash plants are more suitable, and lastly the binary plants are used for hydrothermal well that produces water temperature $<180^{\circ} \mathrm{C}$. In binary cycle, the working fluid other than the geothermal water undergoes a closed cycle, where it evaporates at the heat exchanger, expands in the turbine, condenses in the condenser and it is pumped back to the heat exchanger. Binary plants are often based on ORC or Kalina cycles, whereas the Kalina cycle uses working fluid mixture of water and ammonia $\left(\mathrm{NH}_{3} \mathrm{H}_{2} \mathrm{O}\right)$ which produces two vapour-components at variable temperature, the ORC uses pure organic working fluids with specific evaporation temperature and better matching characteristic with the geothermal fluid, therefore resulting in higher thermodynamic and exergy efficiencies.

Several Scholars have conducted studies on suitable technology options for low-grade heat source utilization such as geothermal, in which ORC is considered the best technology for heat recovery, with cycle modification capable of achieving higher performance [2] [5] [8] [9]. The dual-pressure organic Rankine cycle (DORC) consists of two evaporation processes with different pressure val- 
ues and a condensation process. This can reduce the heat transfer temperature difference between the working fluids and the heat source fluid, significantly decreasing the exergy destruction in the evaporator [2] [3]. Several studies have reported on the performance advantage of the DORC system to the conventional single organic Rankine cycle (SORC). Li et al. [10] investigated the thermodynamic performance of series two-stage ORC (STORC), parallel two-stage ORC (PTORC) and single-pressure ORC (SORC) systems using $90^{\circ} \mathrm{C}-120^{\circ} \mathrm{C}$ geothermal water and R245fa. Results showed an increase in the net power output for the STORC and PTORC compared with the SORC system. Shokati et al. [11] conducted an energy, exergy and exergoeconomic comparative investigation on the SORC, DORC, dual-loop ORC and the Kalina cycle based on heat source temperature of $175^{\circ} \mathrm{C}$. Results showed that the net power output of DORC was $15.2 \%$ higher than the SORC, $35.1 \%$ higher than dual-loop ORC, and $43.5 \%$ higher than the Kalina cycle system. Thierry et al. [12] investigated the performance of DOC using working fluid mixture for heat source temperature range of $90^{\circ} \mathrm{C}-110^{\circ} \mathrm{C}$. Results indicate that DORC efficiency increased by $12.4 \%$ relative to the SORC system. Manente et al. [13] investigated and compared the thermodynamic performance of the SORC and DORC systems driven by geothermal heat source of $100^{\circ} \mathrm{C}-200^{\circ} \mathrm{C}$ temperature range. Results showed DORC gave better performance than SORC, with performance gain of DORC diminishing as heat source temperature increased. Sadeghi et al. [14] evaluated and compared the performance of SORC, STORC and PTORC using zeotropic working fluids and driven by geothermal heatsource temperature of $100^{\circ} \mathrm{C}$. Results showed a $34.3 \%$ net power output increase for STORC relative to the SORC system. Li et al. [15] studied the thermoeconomic performance of ORC with separate and induction turbine layouts, and analyzed the effect of the low-stage and high-stage pressures on the thermoeconomic performance of the system. Results showed that the induction turbine produced better net power output, with significant decrease in the specific investment cost.

There exist in public domain several researches comparing performance of different ORC layouts and system optimization of the DORC. However, a few studies have investigated the exergoeconomic performance of the DORC system with optimization towards optimal system exergy efficiency and minimum product total cost design. Even though DORC systems produces better performance compared with the conventional SORC, their much higher specific investment cost due to their complex configurations consisting of two evaporation processes, two turbine expansion processes and two pumping processes, might be a drawback. Therefore, it is essential to investigate the thermoeconomic and exergoeconomic performance of DORC applications.

The present study, investigates the exergoeconomic optimization of dual-pressure ORC using geothermal heat source. Thermodynamic and thermoeconomic analysis was performed to determine the system first and second law efficiencies, as well as the exergy unit cost rate for each stream. Parametric analysis was also 
conducted to determine the influence of the high-stage and low-stage pressures, working fluids mass flow and heat source temperature on the system overall exergy efficiency and product unit cost. In addition, optimization was performed to obtain optimal decision parameters to attain maximum exergy efficiency optimized design (EEOS case) and minimum product cost optimized design (PCOD case). Finally, to design a cost-efficient system the exergoeconomic parameters like the exergoeconomic factor and cost of exergy destruction were determined for each component in order to identify potential opportunities for system improvement.

\section{System Description}

Figure 1 shows the schematic diagram of the dual-pressure organic Rankine cycle (DORC) driven by geothermal hot water. The ORC system consist of a superheater, the high pressure (HP) and low pressure (LP) evaporators, HP and LP preheaters, HP and LP turbines, an isobaric condenser and the $\mathrm{PH}$ and LP pumps. The LP pump compresses the organic working fluid (state 1) exiting the condenser, the pressurize fluid (state 2) then flows through the preheater 1 where heat from the LP evaporator exit stream is used to increase the fluid enthalpy. The working fluid leaving the preheater is divided into two streams. One part of the organic working fluid flows to the LP evaporator (state 3a) and the other part moves to the HP pump (state $3 b$ ) where it is further compressed to

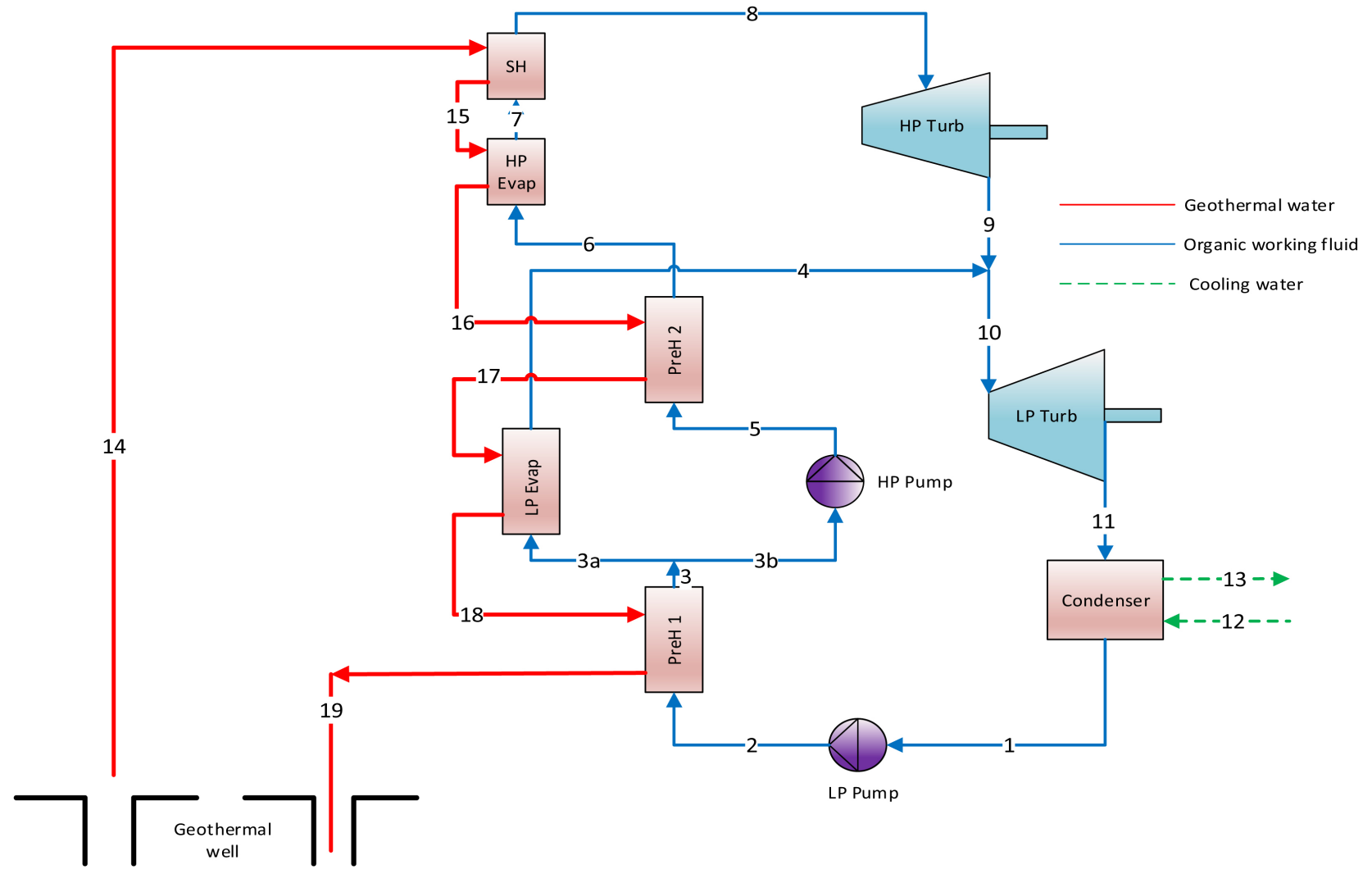

Figure 1. Schematic diagram of dual pressure ORC driven by geothermal heat source. 
high-stage pressure. The compressed fluid from the HP pump (state 5) flows through the preheater 2, absorbing heat before entering the HP evaporator (state 6). The vaporized fluid (state 7) is then superheated before exiting the superheater (state 8) to undergo expansion in the HP turbine. The working fluid leaving the HP turbine (state 9) mixes with the fluid stream from the LP evaporator (state 4) and then flows to the LP turbine inlet (state 10) where it undergoes second turbine expansion. The LP turbine exhaust vapour (state 11) is condensed in the condenser into liquid (state 1) by the cooling water entering (state 12) and leaving (state 13) the condenser. The liquid working fluid (state 1) is then pumped to the preheater 1 and the entire cycle is completed. The geothermal hot water is the heat source that have been used to drive the ORC system. It is a medium-temperature heat source with maximum temperature of $150^{\circ} \mathrm{C}$ at $2525 \mathrm{kPa}$ pressure.

The geothermal resource from the geothermal well (state 14) enters the superheater and exits (state 15) into the HP evaporator where the working fluid is superheated and vaporize, respectively. The hot water streams from HP evaporator (state 16) preheats the high pressure (HP) working fluid in the Preheater 2, then leaves to vaporize (state 17) the low pressure (LP) working fluid. The remaining enthalpy in the hot water leaving (state 18) the LP evaporator is used to preheat the working fluid in preheater 1 , and finally delivered back to the geothermal well (state 19). It is worth noting that, the working fluid pressure leaving the LP evaporator (state 4) is equal to the HP turbine exhaust vapour pressure (state 9).

\section{Thermodynamic Analysis}

For the purpose of system analysis, each component of the DORC is considered a control volume in which mass and energy conservation principles, as well as the second law of thermodynamics are applied. The EES software developed by Ibrahim and Klein [16] have been employed to model all processes in the ORC system.

The following simplified assumptions are further employed in modelling of the ORC:

- The ORC system operates at steady-state condition.

- Pressure drops in all heat exchangers and pipes are negligible.

- Dry and isentropic working fluid at the turbine inlets are superheated vapor.

- Pinch point temperature difference at the heat exchanger is $10^{\circ} \mathrm{C}$.

- Changes in potential and kinetic are negligible.

The mass and energy conservation, as well as exergy balance relations for each system component are represented as [17]:

$$
\begin{gathered}
\sum \dot{m}_{\text {in }}=\sum \dot{m}_{\text {out }} \\
\sum \dot{m}_{\text {in }} h_{\text {in }}+\dot{Q}_{c v}-\sum \dot{m}_{\text {out }} h_{\text {out }}-\dot{W}_{c v}=0 \\
\sum \dot{E}_{\text {in }}-\sum \dot{E}_{\text {out }}+\sum \dot{E}_{\text {heat }}+\sum \dot{W}_{J}-\dot{E}_{D, J}=0
\end{gathered}
$$


Neglecting the potential and kinetic exergies, the total exergy $(\dot{E})$ is considered as the sum of the physical and chemical components expressed as [17]:

$$
\dot{E}=\dot{E}_{p h}+\dot{E}_{c h}
$$

The physical exergy quantifies the maximum obtainable useful work when the system state changes due to variation in pressure and temperature from the specific state $(T, P)$ to reference state $\left(T_{0}, P_{0}\right)$. The specific physical and chemical exergies are expressed as follow:

$$
\begin{gathered}
\dot{E}_{p h}=\dot{m}\left[\left(h-h_{0}\right)-T_{0}\left(s-s_{0}\right)\right] \\
\dot{E}_{c h}=\dot{m}\left[\sum_{i=1}^{n} X_{i} e x_{c h, i}+R T_{0} \sum_{i=1}^{n} X_{i} \operatorname{Ln}\left(X_{i}\right)\right]
\end{gathered}
$$

In the exergy analysis of a system, the product exergy $\left(\dot{E}_{p}\right)$ and fuel exergy $\left(\dot{E}_{f}\right)$ of both the system components and the entire system are calculated separately. For each system component the exergy destruction is defined as the difference between the product and fuel exergies:

$$
\dot{E}_{D, J}=\dot{E}_{f, J}+\dot{E}_{p, J}
$$

The ORC performance evaluates the system energy utilization factor, defined in terms of the thermal efficiency and exergy efficiency.

Thermal efficiency is the ratio of the net power output to the input energy from the geothermal heat source [2]:

$$
\eta_{\text {thermal }}=W_{\text {net }} / Q_{\text {in }}
$$

where,

$$
\begin{gathered}
\dot{W}_{n e t}=\dot{W}_{H P_{-} t u r b}+\dot{W}_{L P_{-} t u r b}-\dot{W}_{\text {pump } 1}-\dot{W}_{\text {pump } 2} \\
\dot{Q}_{\text {in }}=\dot{m}_{14}\left(h_{14}-h_{19}\right)
\end{gathered}
$$

The exergy efficiency is expressed as follows

$$
\eta_{\text {exergy }}=\left(W_{\text {net }}+E_{\text {ref }}\right) / \dot{E}_{\text {in }}
$$

where,

$$
\dot{E}_{\text {in }}=\dot{E}_{14}-\dot{E}_{19}
$$

The overall system efficiency, $\eta_{s y s}$, and the heat recovery effectiveness, $\phi$, of the ORC are calculated as follows:

$$
\begin{gathered}
\eta_{\text {sys }}=Q_{\text {in }} / \dot{m}_{14}\left(h_{14}-h_{0}\right) \\
\phi=W_{\text {net }} / \dot{m}_{14}\left(h_{14}-h_{0}\right)
\end{gathered}
$$

where, $h_{0}$ is specific heat enthalpy of heat source water at ambient temperature.

The energy and exergy relations for each component of the ORC system is shown in Table 1.

\section{Exergoeconomic Analysis}

Exergoeconomic analysis is an approach that combines exergy and economic analyses in order to facilitate better design and more cost-efficient systems. The 
Table 1. Energy and exergy equations for the ORC.

\begin{tabular}{|c|c|c|}
\hline \multirow{2}{*}{ Components } & \multicolumn{2}{|c|}{ Organic Rankine Cycle } \\
\hline & Energy equations & Exergy equation \\
\hline Pump 1 & $\begin{array}{c}\eta_{\text {Pump } 1}=\frac{w_{s}}{w_{A}}=\frac{h_{2 s}-h_{1}}{h_{2}-h_{1}} \\
W_{\text {Pump } 1}=\dot{m}_{1}\left(h_{2}-h_{1}\right)\end{array}$ & $\dot{E}_{1}+\dot{W}_{p \text { pump } 1}-\dot{E}_{2}=\dot{E}_{\text {Destrnction }}$ \\
\hline Pump 2 & $\begin{array}{c}\eta_{P_{\text {Pump } 2}}=\frac{w_{s}}{w_{A}}=\frac{h_{5 s}-h_{3 b}}{h_{5}-h_{3 b}} \\
W_{P_{\text {uump } 2}}=\dot{m}_{5}\left(h_{5}-h_{3 b}\right)\end{array}$ & $\dot{E}_{3 b}+\dot{W}_{\text {pump } 2}-\dot{E}_{5}=\dot{E}_{\text {Destruction }}$ \\
\hline Condenser & $\begin{array}{c}\dot{m}_{\text {cooling }}\left(h_{13}-h_{12}\right)=\dot{m}_{11}\left(h_{11}-h_{1}\right) \\
\dot{Q}_{E c o n}=\dot{m}_{11}\left(h_{11}-h_{1}\right)\end{array}$ & $\dot{E}_{11}+\dot{E}_{12}-\dot{E}_{1}-\dot{E}_{13}=\dot{E}_{\text {Destruction }}$ \\
\hline Superheater & $\begin{array}{c}\dot{m}_{14}\left(h_{14}-h_{15}\right)=\dot{m}_{8}\left(h_{8}-h_{7}\right) \\
\dot{Q}_{\text {SuperH }}=\dot{m}_{8}\left(h_{8}-h_{7}\right)\end{array}$ & $\dot{E}_{14}+\dot{E}_{7}-\dot{E}_{15}-\dot{E}_{8}=\dot{E}_{\text {Destruction }}$ \\
\hline HP Evaporator & $\begin{array}{c}\dot{m}_{15}\left(h_{15}-h_{16}\right)=\dot{m}_{6}\left(h_{7}-h_{6}\right) \\
\dot{Q}_{H P_{\text {Evap }}}=\dot{m}_{6}\left(h_{7}-h_{6}\right)\end{array}$ & $\dot{E}_{15}+\dot{E}_{6}-\dot{E}_{7}-\dot{E}_{16}=\dot{E}_{\text {Destruction }}$ \\
\hline HP Turbine & $\begin{array}{c}\eta_{H P_{-} \text {turb }}=\frac{w_{A}}{w_{s}}=\frac{h_{8}-h_{9}}{h_{8}-h_{9 s}} \\
W_{H P_{-} \text {turb }}=\dot{m}_{8}\left(h_{8}-h_{9}\right)\end{array}$ & $\dot{E}_{8}-\dot{W}_{H P_{-} \text {turb }}-\dot{E}_{9}=\dot{E}_{\text {Destruction }}$ \\
\hline Preheater 1 & $\begin{array}{c}\dot{m}_{18}\left(h_{18}-h_{19}\right)=\dot{m}_{3}\left(h_{3}-h_{2}\right) \\
\dot{Q}_{\text {preH } 1}=\dot{m}_{3}\left(h_{3}-h_{2}\right)\end{array}$ & $\dot{E}_{18}+\dot{E}_{2}-\dot{E}_{19}-\dot{E}_{3}=\dot{E}_{\text {Destruction }}$ \\
\hline LP Evaporator & $\begin{array}{c}\dot{m}_{17}\left(h_{17}-h_{18}\right)=\dot{m}_{4}\left(h_{4}-h_{3 a}\right) \\
\dot{Q}_{L P_{-} \text {Evap }}=\dot{m}_{4}\left(h_{4}-h_{3 a}\right)\end{array}$ & $\dot{E}_{17}+\dot{E}_{3 a}-\dot{E}_{18}-\dot{E}_{4}=\dot{E}_{\text {Destruction }}$ \\
\hline LP Turbine & $\begin{array}{l}\eta_{L P_{-} \text {turb }}=\frac{w_{A}}{w_{s}}=\frac{h_{10}-h_{11}}{h_{10}-h_{11 s}} \\
W_{L P_{-} \text {turb }}=\dot{m}_{10}\left(h_{10}-h_{11}\right)\end{array}$ & $\dot{E}_{10}-\dot{W}_{L P \text { turb }}-\dot{E}_{11}=\dot{E}_{\text {Destruction }}$ \\
\hline Preheater 2 & $\begin{array}{c}\dot{m}_{16}\left(h_{16}-h_{17}\right)=\dot{m}_{5}\left(h_{6}-h_{5}\right) \\
\dot{Q}_{\text {preH } 2}=\dot{m}_{5}\left(h_{6}-h_{5}\right)\end{array}$ & $\dot{E}_{16}+\dot{E}_{5}-\dot{E}_{17}-\dot{E}_{6}=\dot{E}_{\text {Destruction }}$ \\
\hline
\end{tabular}

analysis provides information about the cost formation process and cost of unit exergy of each stream. This analysis is conducted through the formation of cost balance equations and auxiliary equations for each component expressed in the form [11]:

$$
\sum \dot{C}_{i, J}+\dot{C}_{q, J}+\dot{Z}_{J}=\sum \dot{C}_{e, J}+\dot{C}_{w, J}
$$

where,

$$
\dot{C}=c \dot{E}
$$

In the equations above, $\dot{C}$ is the cost rate of exergy ( $\$ \mathrm{hr}$ ) and $c$ is the cost of unit exergy of each stream $(\$ / G J)$. Also, $C_{q}$ and $C_{w}$ represent the heat transfer rate of each component and the work associated costs, respectively. 
The cost balance equation for the entire system is usually formulated as follow [17]:

$$
\dot{C}_{P, \text { total }}=\dot{C}_{f, \text { total }}+\dot{Z}_{\text {total }}
$$

where, $\dot{C}_{P}$ denotes total product related costs, $\dot{C}_{f}$ is the fuel cost rate and $\dot{Z}$ is the total costs related to capital investment and operation and maintenance.

The Investment cost rate $\left(\dot{Z}_{J}\right)$ of $f^{\text {th }}$ component is defined as the sum of the capital investment $\left(\dot{Z}_{J}^{C I}\right)$ and operation and maintenance costs $\left(\dot{Z}_{J}^{O M}\right)$.

$$
\dot{Z}_{J}=\dot{Z}_{J}^{C I}+\dot{Z}_{J}^{O M}
$$

The annual levelized capital investment cost is computed as [17]:

$$
\dot{Z}_{J}=(C R F / \tau) Z_{J}+\left(y_{J} / \tau\right) Z_{J}+\omega_{J} \dot{E}_{P, J}+R_{J} / \tau
$$

where $Z_{J}$ is the capital cost for $J$ component, and is calculated with relations as expressed in Appendix A. $C R F$ denotes the capital recovery factor given as:

$$
C R F=i_{r}\left(1+i_{r}\right)^{n} /\left(\left(1+i_{r}\right)^{n}-1\right)
$$

where, $i_{r}$ is the interest rate, and $n$ is the number of useful years the plant is in operation.

In Equation (19), $\tau$ is the annual hours of plant operation, $y_{J}$ is the fixed cost and $\omega_{J}$ is the variable cost relating to operation and maintenance.

The term $R_{J}$ refers to all other costs independent from investment cost and operation and maintenance costs. The first term in Equation (19) is much larger

\begin{tabular}{|c|c|c|}
\hline \multirow{2}{*}{ Components } & \multicolumn{2}{|c|}{ Organic Rankine cycle } \\
\hline & Cost equations & Auxiliary equation \\
\hline Pump 1 & $\dot{C}_{1}+\dot{C}_{w, p u m p 1}+\dot{Z}_{p u m p 1}=\dot{C}_{2}$ & \\
\hline Condenser & $\dot{C}_{11}+\dot{C}_{12}+\dot{Z}_{c o n d}=\dot{C}_{1}+\dot{C}_{13}$ & $c_{11}=c_{1} ; \quad c_{12}=0$ \\
\hline Preheater 1 & $\dot{C}_{2}+\dot{C}_{18}+\dot{Z}_{p r e H 1}=\dot{C}_{3}+\dot{C}_{19}$ & $c_{2}=c_{3} ; \quad c_{3 a}=c_{3}$ \\
\hline LP Turbine & $\dot{C}_{10}+\dot{Z}_{L P_{-} \text {turb }}=\dot{C}_{11}+\dot{C}_{w, L P_{-} \text {turb }}$ & $\begin{aligned} c_{11} & =c_{10} \\
c_{w, L P_{-} \text {turb }} & =c_{w, p u m p 1}\end{aligned}$ \\
\hline LP Evaporator & $\dot{C}_{3 a}+\dot{C}_{17}+\dot{Z}_{L P_{-} \text {evap }}=\dot{C}_{4}+\dot{C}_{18}$ & $c_{3 a}=c_{4} ; \quad c_{3 a}=c_{3 b}$ \\
\hline Preheater 2 & $\dot{C}_{5}+\dot{C}_{16}+\dot{Z}_{\text {preH } 2}=\dot{C}_{6}+\dot{C}_{17}$ & $c_{5}=c_{6}$ \\
\hline Pump 2 & $\dot{C}_{3 b}+\dot{C}_{w, \text { pump } 2}+\dot{Z}_{\text {pump } 2}=\dot{C}_{5}$ & $\dot{C}_{w, \text { pump } 2}=\dot{C}_{w, p u m p 2}$ \\
\hline HP Turbine & $\dot{C}_{8}+\dot{Z}_{H P_{-} t u r b}=\dot{C}_{9}+\dot{C}_{w, H P_{-} t u r b}$ & $\begin{aligned} c_{9} & =c_{8} \\
c_{w, H P_{-} \text {turb }} & =c_{w, p u m p 2}\end{aligned}$ \\
\hline HP Evaporator & $\dot{C}_{6}+\dot{C}_{15}+\dot{Z}_{H P_{\text {evvap }}}=\dot{C}_{7}+\dot{C}_{16}$ & $c_{6}=c_{7}$ \\
\hline Superheater & $\dot{C}_{7}+\dot{C}_{14}+\dot{Z}_{\text {SuperH }}=\dot{C}_{8}+\dot{C}_{15}$ & $c_{7}=c_{8}$ \\
\hline Mixer & $\dot{C}_{4}+\dot{C}_{9}+\dot{Z}_{\text {mixer }}=\dot{C}_{10}$ & \\
\hline Separator & $\dot{C}_{3}=\dot{C}_{3 a}+\dot{C}_{3 b}$ & $c_{3 a}=c_{3 b}$ \\
\hline
\end{tabular}
than the two last terms, therefore the two last terms can be neglected.

Table 2 shows the cost balance and auxiliary cost equations for each component

Table 2. Component cost balance and auxiliary cost equation of the ORC. 
of the ORC system.

\section{Exergoeconomic Factors}

The exergoeconomic factor $\left(f_{J}\right)$, and the cost of exergy destruction are very important exergoeconomic parameters that are used for evaluating the economic performance of the entire system and each component.

\section{- Exergoeconomic factor $\left(f_{j}\right)$ :}

Exergoeconomic factor $\left(f_{J}\right)$ defines the proportion of capital investment and operation and maintenance costs in the exergy destruction and exergy loss related costs for each component [11] [17].

$$
f_{J}=\dot{Z}_{J} /\left[\dot{Z}_{J}+\left(\dot{C}_{D, J}+\dot{C}_{L, J}\right)\right]
$$

\section{- Cost of exergy destruction:}

The cost of exergy destruction is often referred to as a hidden cost, as it does not appear in the cost balance equation of the components. The cost of exergy destruction, cost of product and cost of fuel can be expressed as follows [18]:

$$
\begin{aligned}
\dot{C}_{D, J} & =c_{f, J} \dot{E}_{D, J} \\
\dot{C}_{P, J} & =c_{p, J} \dot{E}_{P, J} \\
\dot{C}_{F, J} & =c_{f, J} \dot{E}_{F, J}
\end{aligned}
$$

where $c_{f}$ and $c_{p}$ denotes average cost per unit fuel and the cost per unit product for each component.

\section{Model Verification}

The thermodynamic model developed for the DORC system being investigated is first validated against available public literature [20]. A comparison of the results obtained in present work with those reported in Manente et al. [20] is shown in Table 3. It is observed that there is a good agreement between results obtained from present study and those reported in literature.

The Input data and assumptions made for the parametric study of the DORC system is listed in Table 4.

\subsection{Results and Discussion}

The thermodynamic properties, exergy rate $\dot{E}$, exergy cost rate $\dot{C}[\$ / \mathrm{hr}]$ and cost rate of unit exergy $c[\$ / G J]$ at each stream for the developed model of the DORC system based on the input conditions listed in Table 4 is presented in Table 5. It can be observed that the cost per unit exergy for the superheater, evaporators and preheaters have the highest values. This is due to the high heat losses experienced in these components. Table 6 presents a summary of the exergy of fuel (i.e. input exergy) $\dot{E}_{f}$, exergy of product $\dot{E}_{p}$, exergy destruction rate $\dot{E}_{D}$, and exegetic efficiency $\varepsilon$, of individual components of the DORC base case. The condenser has the highest value of exergy destruction rate compared to other components, and with a corresponding component exegetic 
Table 3. Comparison of the results from present models with those reported in [19].

\begin{tabular}{ccccc}
\hline \multirow{2}{*}{ Parameters } & \multicolumn{3}{c}{ Working fluid-Isobutane } \\
\cline { 2 - 5 } & Present Work & Manente et al. [19] & Relative error [\%] \\
\hline$T_{\text {Sat } H P}\left[{ }^{\circ} \mathrm{C}\right]$ & 113.40 & 113.30 & +0.088 \\
$T_{S a t_{-} L P}\left[{ }^{\circ} \mathrm{C}\right]$ & 76.57 & 76.60 & -0.039 \\
$P_{H P}$ & {$[\mathrm{KPa}]$} & 2525 & 2530 & -0.198 \\
$P_{L P}$ & {$[\mathrm{KPa}]$} & 1230 & 1230 & 0.0 \\
$\dot{m}_{H P}$ & {$[\mathrm{Kg} / \mathrm{s}]$} & 62.90 & 62.90 & 0.0 \\
$\dot{m}_{L P}[\mathrm{Kg} / \mathrm{s}]$ & 32.74 & 32.80 & -0.183 \\
$\eta_{t h}[\%]$ & 10.59 & 10.22 & +3.493 \\
$\eta_{s y s}[\%]$ & 7.026 & 7.066 & -0.569 \\
$W_{n e t}$ & {$[\mathrm{KW}]$} & 3859 & 3871 & -0.310 \\
\hline
\end{tabular}

Table 4. The DORC system input data.

\begin{tabular}{lc}
\hline \multicolumn{1}{c}{ Parameters } & Values \\
\hline Ambient Temperature, $T_{\text {amb }}$ & $20\left[{ }^{\circ} \mathrm{C}\right]$ \\
Ambient Pressure, $P_{\text {amb }}$ & $101[\mathrm{kPa}]$ \\
Geothermal Water Temperature, $T_{14}$ & $150\left[{ }^{\circ} \mathrm{C}\right]$ \\
Geothermal Water Pressure, $P_{14}$ & $2525[\mathrm{kPa}]$ \\
Geothermal water mass flow rate, $\dot{m}_{14}$ & $45[\mathrm{Kg} / \mathrm{s}]$ \\
Pinch point temperature difference in the evaporator, $\Delta_{\text {Evap }}$ & $10\left[{ }^{\circ} \mathrm{C}\right]$ \\
Cooling water entry temperature, $T_{12}$ & $25\left[{ }^{\circ} \mathrm{C}\right]$ \\
Condensation temperature, $T_{\text {cond }}$ & $29\left[{ }^{\circ} \mathrm{C}\right]$ \\
Pinch point temperature difference in the condenser,,$\Delta T_{\text {cond }}$ & $10\left[{ }^{\circ} \mathrm{C}\right]$ \\
Turbine efficiency, $\eta_{\text {turb }}$ & $85[\%]$ \\
Pump efficiency, $\eta_{\text {pump }}$ & $70[\%]$ \\
Annual operating hours, $\tau$ & $8000[\mathrm{hr} . /$ year $]$ \\
Interest rate, $i_{r}$ & $15[\%]$ \\
Plant years of operation, $n$ & 20 years \\
\hline
\end{tabular}

efficiency of $99.87 \%$.

After the condenser, the next components with significant contribution to the cycle exergy destruction rate are the HP evaporator, LP turbine and preheater 1, with exergy efficiencies of $99.91 \%, 98.92 \%$ and $99.98 \%$, respectively.

The DORC base case exergoeconomic parameters are presented in Table 7. From exergoeconomic analysis viewpoint, components with the highest value of $\dot{Z}+\dot{C}_{D}$ should be treated with higher impotence in terms of implementing component improvement effort. Therefore, the LP turbine is of higher importance from exergoeconomic viewpoint. The high value of $f$ indicates that the HP evaporator cost rates associated with capital investment cost dominates the contribution associated with exergy destruction in the LP turbine. To reduce the value of $\dot{Z}+\dot{C}_{D}$ for the LP turbine, capital investment cost should be reduce by 
Table 5. Thermodynamic flow parameters, exergy flow rates, cost flow rates and unit cost of exergy for Isobutane.

\begin{tabular}{|c|c|c|c|c|c|c|c|}
\hline State & $\begin{array}{l}\text { Working } \\
\text { Fluid }\end{array}$ & $\begin{array}{c}T \\
{\left[{ }^{\circ} \mathrm{C}\right]}\end{array}$ & $\begin{array}{c}P \\
{[\mathrm{KPa}]}\end{array}$ & $\begin{array}{c}\dot{\boldsymbol{m}} \\
{[\mathrm{Kg} / \mathrm{s}]}\end{array}$ & $\begin{array}{c}\dot{\boldsymbol{E}}_{e x} \\
{[\mathrm{MW}]}\end{array}$ & $\begin{array}{c}\dot{C} \\
{[\$ / \mathrm{h}]}\end{array}$ & $\begin{array}{c}c \\
{[\$ / G J]}\end{array}$ \\
\hline 1 & Isobutane & 39.00 & 517 & 43.34 & 8.238 & 154.40 & 5.205 \\
\hline 2 & Isobutane & 39.67 & 1250 & 43.34 & 8.322 & 161.40 & 5.389 \\
\hline 3 & Isobutane & 76.57 & 1250 & 43.34 & 12.371 & 188.30 & 4.229 \\
\hline 4 & Isobutane & 76.57 & 1250 & 14.48 & 7.658 & 86.42 & 3.135 \\
\hline 5 & Isobutane & 78.19 & 2525 & 28.87 & 8.347 & 135.70 & 4.517 \\
\hline 6 & Isobutane & 113.3 & 2525 & 28.87 & 11.407 & 158.10 & 3.850 \\
\hline 7 & Isobutane & 113.3 & 2525 & 28.87 & 16.176 & 190.00 & 3.263 \\
\hline 8 & Isobutane & 114.3 & 2525 & 28.87 & 16.278 & 194.50 & 3.319 \\
\hline 9 & Isobutane & 82.45 & 1250 & 28.87 & 15.646 & 186.90 & 3.319 \\
\hline 10 & Isobutane & 80.48 & 1250 & 43.34 & 23.303 & 436.70 & 5.205 \\
\hline 11 & Isobutane & 52.42 & 517 & 43.34 & 21.979 & 411.90 & 5.205 \\
\hline 12 & Water & 25.00 & 101 & 877.30 & 17.108 & 0 & 0 \\
\hline 13 & Water & 29.00 & 101 & 877.30 & 30.809 & 264.60 & 2.386 \\
\hline 14 & Water & 150.00 & 2525 & 45.00 & 23.345 & 115.40 & 1.373 \\
\hline 15 & Water & 149.40 & 2525 & 45.00 & 23.243 & 114.90 & 1.373 \\
\hline 16 & Water & 123.30 & 2525 & 45.00 & 18.460 & 91.24 & 1.373 \\
\hline 17 & Water & 106.30 & 2525 & 45.00 & 15.391 & 76.07 & 1.373 \\
\hline 18 & Water & 86.57 & 2525 & 45.00 & 11.854 & 58.59 & 1.373 \\
\hline 19 & Water & 63.69 & 2525 & 45.00 & 7.792 & 38.51 & 1.373 \\
\hline
\end{tabular}

Table 6. Results of exergy analysis of the DORC system components.

\begin{tabular}{ccccc}
\hline \multirow{2}{*}{ Components } & \multicolumn{3}{c}{ Exergy Parameters } \\
\cline { 2 - 5 } & $\dot{\boldsymbol{E}}_{p}[\mathrm{KW}]$ & $\dot{\boldsymbol{E}}_{f}[\mathrm{KPa}]$ & $\dot{\boldsymbol{E}}_{\boldsymbol{D}}[\mathrm{KW}]$ & $\varepsilon \quad[\%]$ \\
\hline HP Turbine & $626.1^{\mathrm{a}}$ & 632.4 & 6.229 & 99.02 \\
LP Turbine & 1310.0 & 1325.0 & 14.270 & 98.92 \\
Condenser & $30,809.0$ & $30,849.0$ & 39.110 & 99.87 \\
LP Pump 1 & 8322.0 & 8323.0 & 1.637 & 99.98 \\
Preheater 1 & $12,371.0$ & $12,384.0$ & 12.59 & 99.90 \\
LP Evaporator & 7658.0 & 7669.0 & 11.470 & 99.85 \\
HP Pump 2 & 8347.0 & 8349.0 & 1.884 & 99.98 \\
Preheater 2 & $11,407.0$ & $11,416.0$ & 8.323 & 99.93 \\
HP Evaporator & $16,176.0$ & $16,191.0$ & 14.640 & 99.91 \\
Superheater & $16,278.0$ & $16,279.0$ & 0.4564 & 100.00 \\
\hline
\end{tabular}


Table 7. Results of exergoeconomic parameters of the DORC system components.

\begin{tabular}{ccccccc}
\hline & \multicolumn{5}{c}{ Exergoeconomic Parameters } \\
\cline { 2 - 7 } Components & $\boldsymbol{c}_{p}$ & $\boldsymbol{c}_{f}$ & $\dot{\boldsymbol{C}}_{\boldsymbol{D}}$ & $\dot{\boldsymbol{Z}}_{J}$ & $\dot{\boldsymbol{Z}}_{J}+\dot{\boldsymbol{C}}_{\boldsymbol{D}, J}$ & $\boldsymbol{f}$ \\
& {$[\$ / \mathrm{GJ}]$} & {$[\$ / \mathrm{GJ}]$} & {$[\$ / \mathrm{hr}]$} & {$[\$ / \mathrm{hr}]$} & {$[\$ / \mathrm{hr}]$} & {$[\%]$} \\
\hline HP Turbine & 9.979 & 3.319 & 0.07441 & 14.940 & 15.010 & 99.50 \\
LP Turbine & 9.979 & 5.205 & 0.26730 & 22.250 & 22.520 & 98.81 \\
Condenser & 2.386 & 2.319 & 0.32640 & 7.139 & 7.465 & 95.63 \\
LP Pump 1 & 5.389 & 5.254 & 0.03096 & 4.003 & 4.034 & 99.23 \\
Preheater 1 & 4.229 & 4.072 & 0.18450 & 6.831 & 7.016 & 97.37 \\
LP Evaporator & 3.135 & 2.912 & 0.12020 & 6.024 & 6.144 & 98.04 \\
HP Pump 2 & 4.517 & 4.305 & 0.02919 & 6.349 & 6.378 & 99.54 \\
Preheater 2 & 3.850 & 3.672 & 0.11000 & 7.208 & 7.318 & 98.50 \\
HP Evaporator & 3.263 & 3.118 & 0.16440 & 8.240 & 8.404 & 98.04 \\
Superheater & 3.319 & 3.251 & 0.00534 & 3.968 & 3.968 & 99.87 \\
\hline
\end{tabular}

using cheaper turbine. The next components with the highest $\dot{Z}+\dot{C}_{D}$ value are the HP turbine, HP evaporator and condenser in descending order, respectively. In the same manner, in HP turbine the capital investment cost $\dot{Z}_{L P_{-} \text {turb }}$ value dominates the contribution associated with exergy destruction $\dot{C}_{D, H P_{-} t u r b}$.

This implies, lowering the value of $\dot{Z}+\dot{C}_{D}$ in the HP turbine would come by choosing turbine with lower capital investment cost.

Other components are observed to follow similar trend. The high value of $f$ for these components indicates that the capital investment cost $\dot{Z}$, is larger than the cost rate associated with exergy destruction $\dot{C}_{D}$. Therefore, any further reduction in the value of $\dot{Z}+\dot{C}_{D}$ parameter can be achieved by lowering the capital investment cost of the components.

Comparing the processes involving compression in the pump, expansion in the turbines and heat transfer in the superheater, evaporators and preheaters, the LP pump1 and superheater are observed to have lower value of rate of exergy destruction $\dot{E}_{D}$ than other components in the DORC. The superheater and LP pump1 also appears to have lower value of $\dot{Z}+\dot{C}_{D}$ compare to other components of the cycle, in which superheater has the lowest value of $\dot{Z}+\dot{C}_{D}$, which is understandable considering the degree $\left(1^{\circ} \mathrm{C}\right)$ of superheating in the base case. Therefore, the LP pump1 and superheater are considered the cheapest components in the cycle with minimum values of $\dot{Z}+\dot{C}_{D}$ and having no significant effect on the exergoeconomic performance of the cycle given any changes in the component. It is also observed that all the components where heat transfer process occur except in the superheater, have high rate of exergy destruction $\dot{E}_{D}$ with corresponding high cost associated with exergy destruction $\dot{C}_{D}$.

\subsection{Parametric Study}

In this section, an investigation on the effect of operating parameters on the 
cycle thermodynamic and exergoeconomic performance is undertaken. Figure 2 shows the influence of HP and LP pressures variation on the DORC thermal efficiency and cycle power outputs. Analysis indicates that, as HP pressure increases while LP pressure is held constant, the power output of the HP turbine decreases.

Thermal efficiency: Figure 2(a) shows the variation of thermal efficiency $\left(\eta_{t h}\right)$ with respect to changes in $P_{H P}$ and $P_{L P}$ pressures. The $\eta_{t h}$ trend terns to gradually decrease as the value of $P_{H P}$ rises and sharply increases with $P_{L P}$ rise. This is because the increase in $P_{L P}$ leads to a decrease in heat source utilization rate and increase in $T_{19}$ temperature. That is, as $P_{L P}$ increases heat absorbed in the HP evaporator $\dot{Q}_{H P E}$ decreases, heat absorbed in the LP evaporator $\dot{Q}_{L P E}$ decreases and heat absorbed in the LP preheater $1 \dot{Q}_{\text {preH } 1}$ increases at first and then decrease. Since the total amount of heat $\dot{Q}_{\text {Total }}$ absorbed by the

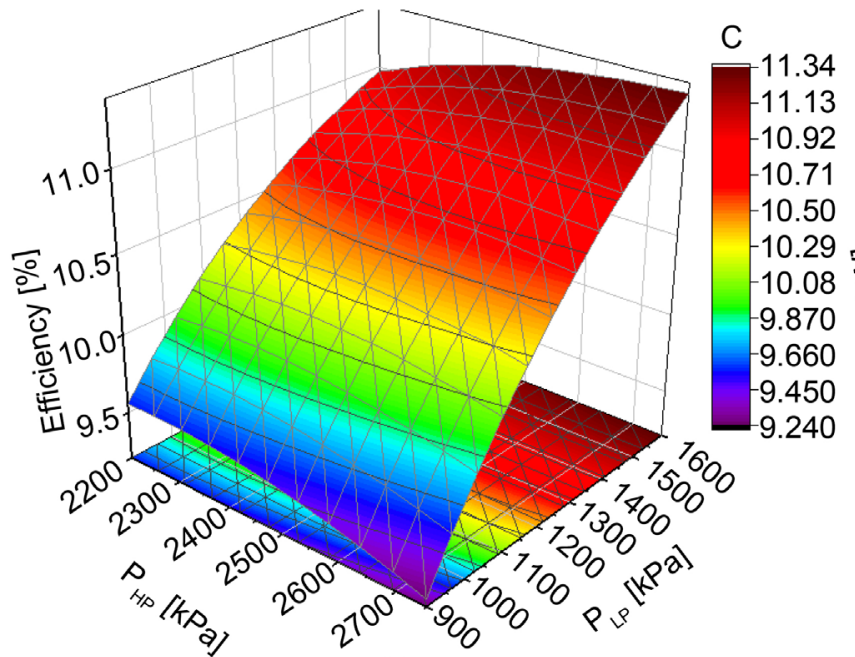

(a)

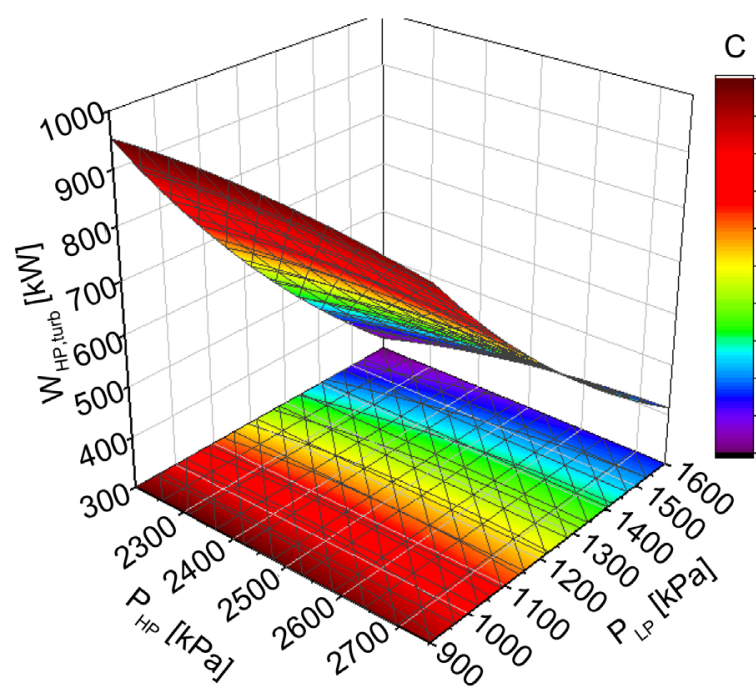

(c)

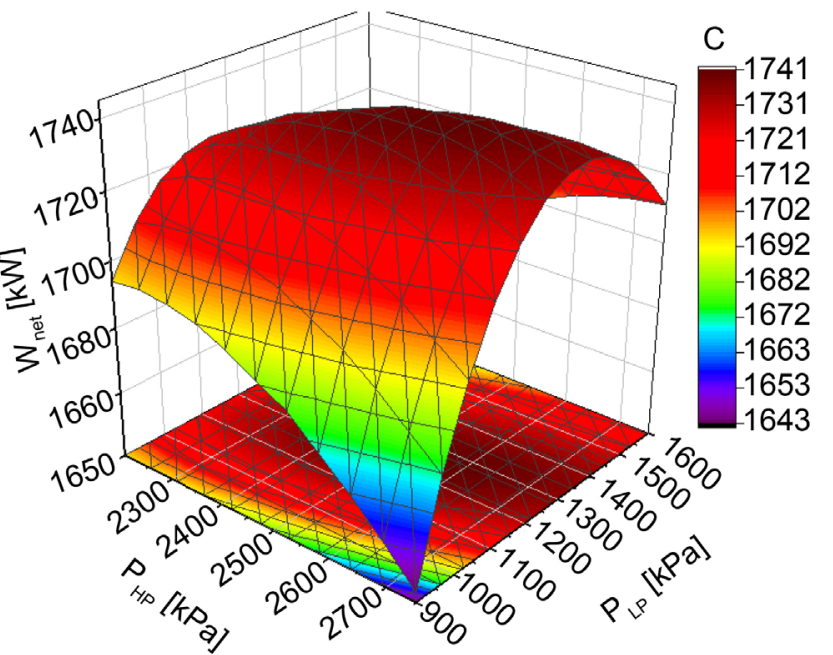

(b)

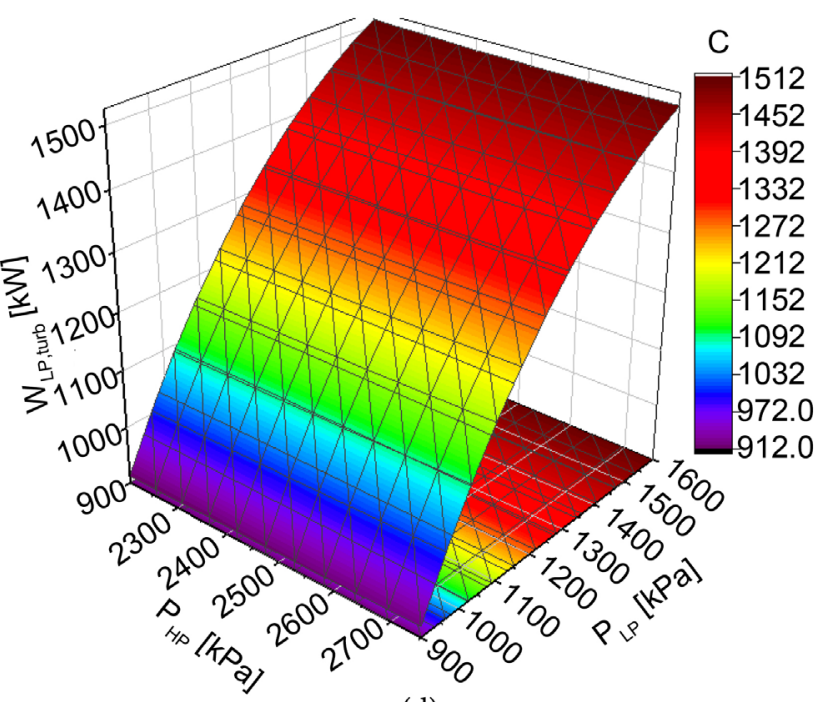

(d)

Figure 2. (a) Thermal efficiency $\left(\eta_{t h}\right)$ over $P_{H P}$ and $P_{L P}$ variation. (b) Net power output $\left(\dot{W}_{n e t}\right)$ over $P_{H P}$ and $P_{L P}$ variation. (c) $\dot{W}_{H P_{-} t u r b}$ over $P_{H P}$ and $P_{L P}$ variation. (d) $\dot{W}_{L P_{-} t u r b}$ over $P_{H P}$ and $P_{L P}$ variation. 
cycle is determined by $\dot{Q}_{H P E}$ and $\dot{Q}_{\text {preH1 }}$, in which the value of $\dot{Q}_{H P E}$ dominants the value of $\dot{Q}_{\text {Total }}$, which decreases at first and then increases afterwards. Therefore, causing thermal efficiency $\eta_{t h}$ to increase as the value of $P_{L P}$ increases. The highest $\eta_{t h}$ is observed within the range $2450 \mathrm{kPa}<P_{H P}<2750 \mathrm{kPa}$ and $1400 \mathrm{kPa}<P_{L P}<1600 \mathrm{kPa}$ (see Figure 2(a)).

Net power output: Figure 2(b) illustrates the effect of $P_{H P}$ and $P_{L P}$ pressure variation on the DORC system net power output. It can be observed, that when $P_{H P}$ increases the value of $\dot{W}_{n e t}$ decreases, whereas the rise in $P_{L P}$ causes $\dot{W}_{n e t}$ to increase at first and then declined afterward. This trend is due to the different responses of $\dot{W}_{H P_{-} \text {turb }}$ and $\dot{W}_{L P_{-} \text {turb }}$ to changes in $P_{H P}$ and $P_{L P}$.

As $P_{L P}$ increases while $P_{H P}$ is held constant, the value of $\dot{W}_{H P_{-} t u r b}$ decreases (Figure 2(c)) while $\dot{W}_{L P_{-} \text {turb }}$ increases steadily (Figure 2(d)). Similarly, as $P_{H P}$ increases while $P_{L P}$ is constant, the value of $\dot{W}_{H P_{-} t u r b}$ decreases gradually while $\dot{W}_{L P_{-} \text {turb }}$ is reasonably unchanged. These effects lead to an initial increase in the value of $\dot{W}_{\text {net }}$ and a decline afterward as $P_{L P}$ increases and a steady decline in $\dot{W}_{n e t}$ as $P_{H P}$ increases. The higher value of $\dot{W}_{\text {net }}$ can be observed in the range of $1000 \mathrm{kPa}<P_{L P}<1500 \mathrm{kPa}$ and $2300 \mathrm{kPa}<P_{H P}<2500 \mathrm{kPa}$ as indicated in Figure 2(b). $\eta_{t h}$ and $\dot{W}_{\text {net }}$ results presented show strong agreement with findings in [2].

Figure 3 shows variation in exergoeconomic parameters such as $\dot{C}_{D, \text { overall }}$, $\dot{Z}_{\text {overall }}, \dot{C}_{D, \text { overall }}+\dot{Z}_{\text {overall }}, f_{\text {overall }}$ and $c_{w, \text { turb }}$ over changes in the high-stage pressure $\left(P_{H P}\right)$ and low-stage pressure $\left(P_{L P}\right)$ of the cycle. Table 7 indicates that the $\dot{Z}+\dot{C}_{D}$ value of the LP turbine, HP turbine and HP evaporator have the largest influence on the exergoeconomic performance of the cycle. If the value of $P_{H P}$ is increased while $P_{L P}$ is held constant, the values of $\dot{C}_{10}, \dot{C}_{11}$ and $\dot{C}_{D, L P \text { turb }}$ will have a slight decreasing trend while the LP turbine capital investment cost $\dot{Z}_{L P \text { turb }}$ remaining fairly constant. The values of $\dot{C}_{8}$ and $\dot{Z}_{H P_{-} \text {turb }}$ takes a descending trend and the value of $\dot{C}_{D, H P_{-} \text {turb }}$ is observed to slightly increase. The values of $\dot{C}_{6}, \dot{C}_{7}, \dot{Z}_{H P_{\text {evap }}}$ and $\dot{C}_{D, H P \text { evap }}$ all takes a descending trend.

If the $P_{L P}$ is increased while $P_{H P}$ is kept constant, the values of $\dot{C}_{10}, \dot{C}_{11}$, $\dot{Z}_{L P_{\text {P turb }}}$ and $\dot{C}_{D, L P \text { turb }}$ showing similar trend, increasing steadily as $P_{L P}$ increases. The value of $\dot{C}_{8}$ increases, the $\dot{Z}_{H P_{-} \text {turb }}$ show a declining trend, while the parameter $\dot{C}_{D, H P \text { turb }}$ ascend at first and then descend afterward. The $\dot{C}_{6}, \dot{C}_{7}$ and HP evaporator cost rate associate with exergy destruction $\dot{C}_{D, H P_{-} E v a p}$ show slight increase and the parameter $\dot{Z}_{H P_{-} E v a p}$ remains unchanged. It is obvious that changes in these component parameters can significantly influences the overall exergoeconomic performance of the DORC system.

In the case of $P_{H P}$ increasing and $P_{L P}$ constant, the $\dot{C}_{D}$ shows a descending trend for the LP turbine and HP evaporator and an increasing trend for HP turbine. These components account for up to half of the value of the overall cost rate associated with exergy destruction, $\dot{C}_{D, \text { overall }}$, therefore affecting the behavior of $\dot{C}_{D, \text { overall }}$. Figure $3\left(\right.$ a) shows that the value of $\dot{C}_{D, \text { overall }}$ decreases as $P_{H P}$ 


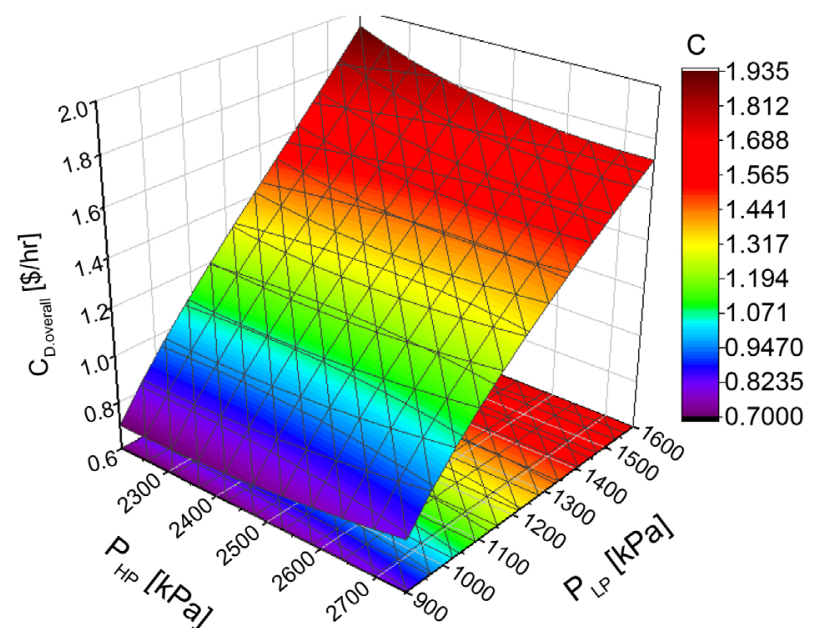

(a)

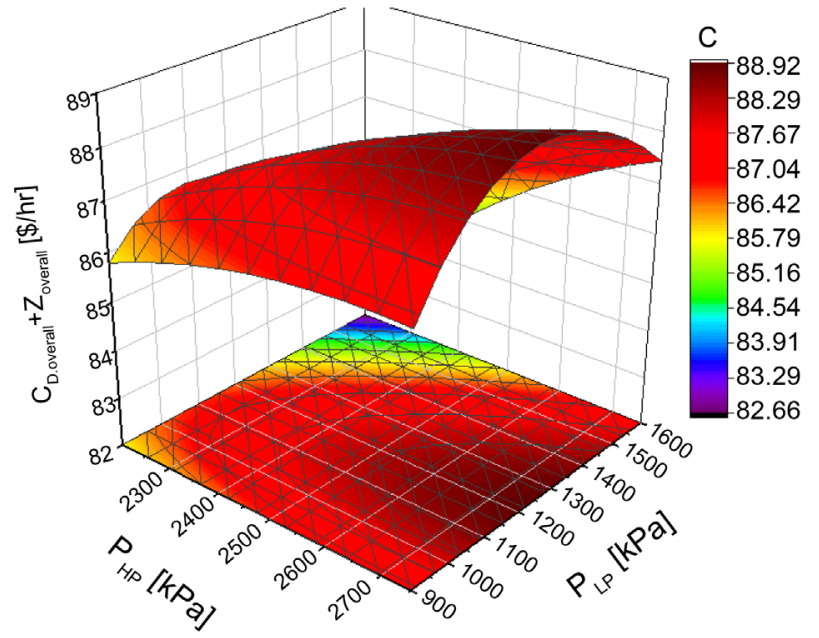

(c)

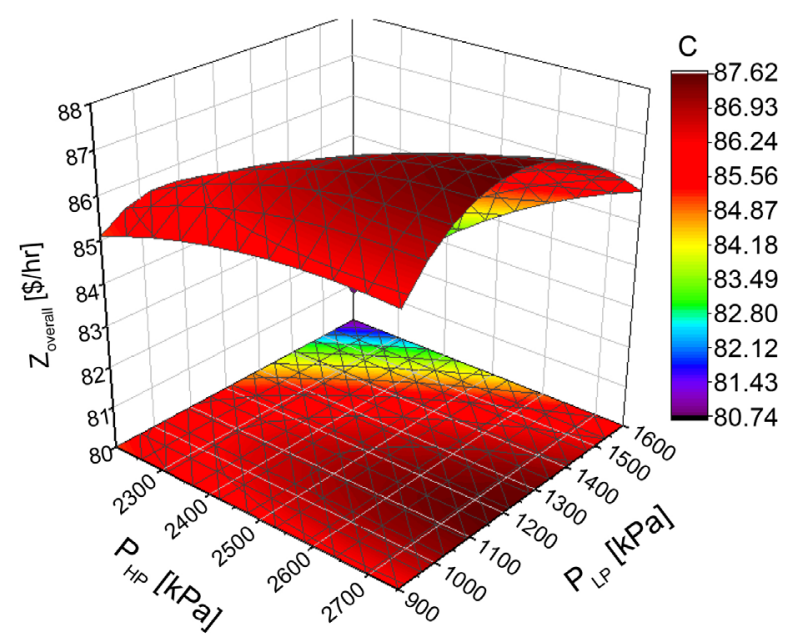

(b)

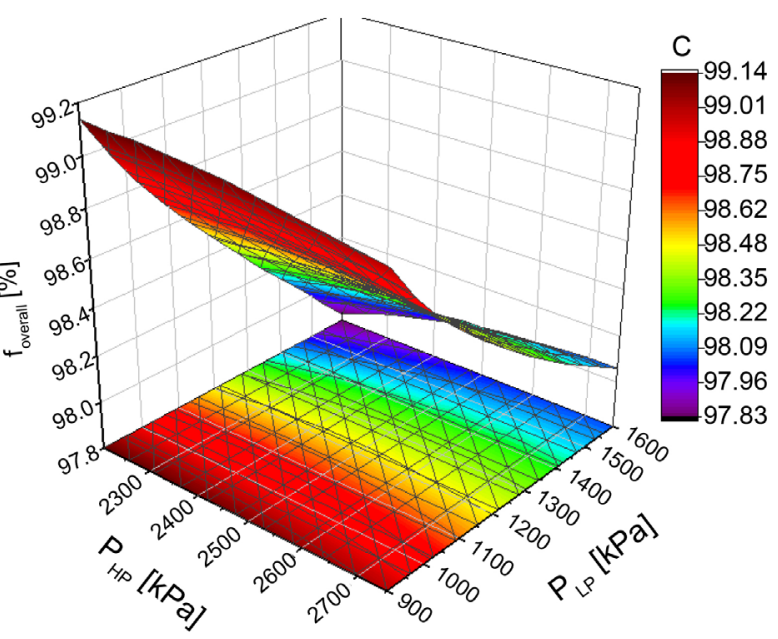

(d)

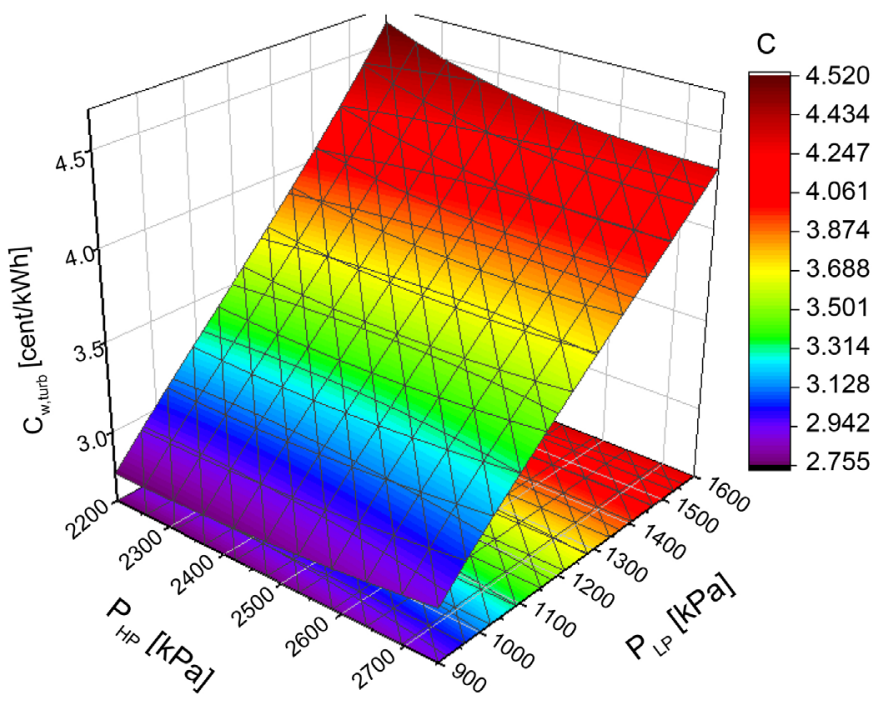

(e)

Figure 3. (a) $\dot{C}_{D, \text { vverall }}$ over $P_{H P}$ and $P_{L P}$ variation. (b) $\dot{Z}_{\text {overall }}$ over $P_{H P}$ and $P_{L P}$ variation. (c) $\dot{C}_{D, \text { vverall }}+\dot{Z}_{\text {overall }}$ over $P_{H P}$ and $P_{L P}$ variation. (d) $f_{\text {overall }}$ over $P_{H P}$ and $P_{L P}$ variation. (e) $c_{w, \text { turb }}$ over $P_{H P}$ and $P_{L P}$ variation. 
is increased and $P_{L P}$ is constant. This indicate that $\dot{C}_{D, L P \_t u r b}, \dot{C}_{D_{, H P} \text { evap }}$ and other components with descending trend have stronger influence on the behavior of $\dot{C}_{D \text {,overall }}$. The $\dot{Z}_{\text {overall }}$ trend is observed to first increase and then decrease as $P_{H P}$ is increased and $P_{L P}$ held constant (Figure 3(b)). The trend of $\dot{Z}_{\text {overall }}$ can be attributed to the behavior of $\dot{Z}_{H P_{-} \text {turb }}$ and $\dot{Z}_{H P_{-} \text {evap }}$. Since the value $\dot{Z}_{\text {overall }}$ is greater than that of $\dot{C}_{D \text {,overall }}$, the $\dot{C}_{D \text {,overall }}+\dot{Z}_{\text {overall }}$ parameter have similar trend as the $\dot{Z}_{\text {overall }}$ parameter, ascending at first and then descending as $P_{H P}$ increases (Figure $3(\mathrm{c})$ ). The value of $f_{\text {overall }}$ parameter, which is the ratio of $\dot{Z}_{\text {overall }}$ and $\dot{C}_{D \text {,overall }}+\dot{Z}_{\text {overall }}$ show decreasing trend as $P_{H P}$ increases. The unit cost of power produced $c_{w, t u r b}$ show slight decrease as $P_{H P}$ increases.

If $P_{L P}$ is increased and $P_{H P}$ is held constant, the value of $\dot{C}_{D}$ for components with significant influence on the behavior of $\dot{C}_{D, \text { overall }}$ such as the LP turbine and HP evaporator show an increasing trend.

This results in the ascending trend of $\dot{C}_{D \text {,overall }}$ as $P_{L P}$ increases. In the other hand, the $\dot{Z}_{\text {overall }}$ parameter have similar behavior as previous, increasing at first and then decreasing. $\dot{C}_{D, \text { overall }}+\dot{Z}_{\text {overall }}$ also takes a similar trend due to the dominant influence of $\dot{Z}$. The $f_{\text {overall }}$ parameter show increasing trend with increase in $P_{L P}$, reflecting the dominance of $\dot{Z}_{\text {overall }}$ in the $\dot{C}_{D \text {,overall }}+\dot{Z}_{\text {overall }}$ parameter.

\subsection{Optimization}

The DORC system optimization is considered in this section to determine the optimal design (working conditions) from the viewpoint of the exergy efficiency optimal design (EEOD), and the minimum unit cost of product cost optimal design (PCOD) using the direct search method in EES software. Six decision parameters with the range of variation shown below were considered to optimize the system:

$$
\begin{gathered}
2200 \mathrm{kPa} \leq P_{H P} \leq 2750 \mathrm{kPa} \\
900 \mathrm{kPa} \leq P_{L P} \leq 1600 \mathrm{kPa} \\
1^{\circ} \mathrm{C} \leq \Delta T_{S H} \leq 10^{\circ} \mathrm{C} \\
25^{\circ} \mathrm{C} \leq T_{\text {cond, out }} \leq 29^{\circ} \mathrm{C} \\
1^{\circ} \mathrm{C} \leq \Delta T_{\text {cond, }, p p} \leq 10^{\circ} \mathrm{C} \\
5^{\circ} \mathrm{C} \leq \Delta T_{\text {Evap }, p p} \leq 15^{\circ} \mathrm{C}
\end{gathered}
$$

The results of the optimization presented in Table 8, compares the performance of the base case, EEOD and PCOD cases. The exergy efficiency in the EEOD case is $33.03 \%$ which is $0.3 \%$ and $0.1 \%$ higher than the values obtained from the base cases and the PCOD case, respectively. The thermal efficiency in the EEOD case is $11.3 \%$, which is $6.19 \%$ and $4.24 \%$ higher than the base case and PCOD, respectively. The net power produced in the EEOD case is $1939 \mathrm{~kW}$, which is $10.2 \%$ higher than the base case and $2.24 \%$ lower than the PCOD case, respectively. With regards to the minimum unit cost product/power optimal 
Table 8. Results of optimization.

\begin{tabular}{cccc}
\hline \multirow{2}{*}{ Parameters } & Base case & EEOD & PCOD \\
\cline { 2 - 4 } & 2525 & 2481 & 2590 \\
\hline$P_{H P}[\mathrm{~Pa}]$ & 1250 & 1200 & 1059 \\
$P_{L P}[\mathrm{~Pa}]$ & 1 & 1 & 1 \\
$\Delta T_{S H}[\mathrm{C}]$ & 10 & 10 & 5 \\
$\Delta T_{\text {Evap_pp }}[\mathrm{C}]$ & 10 & 5 & 6.66 \\
$\Delta T_{\text {cond_pp }}[\mathrm{C}]$ & 32.93 & 33.03 & 33 \\
$\eta_{e x}[\%]$ & 10.6 & 11.3 & 10.82 \\
$\eta_{t h}[\%]$ & 1741 & 1939 & 1991 \\
$W_{n e t}[\mathrm{~kW}]$ & 3.592 & 3.507 & 3.059 \\
$c_{w, \text { turb }}$ & 66.39 & 69.38 & 74.39 \\
$\theta \quad[\%]$ & 7.039 & 7.841 & 8.05 \\
$\eta_{s s s}[\%]$ & 877.3 & 909.7 & 692.9 \\
$\dot{m}_{\text {cooling }}[\mathrm{kg} / \mathrm{s}]$ & 28.87 & 29.43 & 33.56 \\
$\dot{m}_{H P}[\mathrm{~kg} / \mathrm{s}]$ & 14.48 & 14.5 & 14.58 \\
$\dot{m}_{L P}[\mathrm{~kg} / \mathrm{s}]$ & & &
\end{tabular}

design (PCOD) case, the $c_{w, t u r b}$ parameteris 3.059 cent $/ \mathrm{kWh}$, which is $17.4 \%$ and $14.64 \%$ lower than the base case and EEOD case, respectively. The net power output in the PCOD case is $1991 \mathrm{~kW}$, which is $12.55 \%$ and $2.6 \%$ higher than base case and the EEOD case, respectively. It is apparent from Table 8, that in PCOD case both unit cost of product and net power produced are higher compared to the base case and EEOD case.

In Table 9, comparative assessment of the base case, EEOD and PCOD cases from a thermoeconomic viewpoint is presented. The analysis identifies the optimal design and components with the highest exergy destruction rate and exergoeconomic factors for component optimization and system improvement. The base case is observed to have the highest value of $\dot{E}_{D, \text { overall }}(110.609 \mathrm{~kW})$, which is $7.36 \%$ and $6.53 \%$ higher than the EEOD and PCOD cases, respectively. The condenser has the highest contribution to the cycle total rate of exergy destruction and the superheater having the minimum contribution for all three cases.

The HP evaporator, LP turbine and condenser are observed to have the highest value of cost rate associated with exergy destruction $\dot{C}_{D}$, and the HP turbine and superheater having the lowest value. The components in Table 9 are being arranged in descending order of their $\dot{Z}+\dot{C}_{D}$ value. Results indicate that the HP evaporator and LP turbine have the highest values, this means that focus will be place on these components in terms of optimization and modification for component improvement and cost effectiveness. The high value for exergoeconomic factor $f$ observed, indicates that the capital investment costs $\dot{Z}$ for these components are larger than the contribution of the cost rate associated with exergy destruction in the $\dot{Z}+\dot{C}_{D}$ parameter. Therefore, to lower value of 
Table 9. Results of exergoeconomic analysis for base case, EEOD and PCOD.

\begin{tabular}{|c|c|c|c|c|c|c|c|c|c|c|c|c|c|c|c|}
\hline \multirow{3}{*}{ Components } & \multicolumn{3}{|c|}{$\begin{array}{l}\text { Rate of exergy } \\
\text { destruction }\end{array}$} & \multicolumn{3}{|c|}{$\begin{array}{c}\text { Cost rate of } \\
\text { exergy destruction }\end{array}$} & \multicolumn{3}{|c|}{$\begin{array}{l}\text { Cost rate of } \\
\text { Investment }\end{array}$} & \multicolumn{3}{|c|}{$\dot{C}_{D, J}+\dot{Z}_{J} \quad(\$ / \mathrm{hr})$} & \multirow{2}{*}{\multicolumn{3}{|c|}{$\begin{array}{c}\begin{array}{c}\text { Exergoeconomic } \\
\text { factors }\end{array} \\
f(\%)\end{array}$}} \\
\hline & \multicolumn{3}{|c|}{$\dot{E}_{D, J}(\mathrm{KW})$} & \multicolumn{3}{|c|}{$\dot{C}_{D, J}(\$ / \mathrm{hr})$} & \multicolumn{3}{|c|}{$\dot{Z}_{J}(\$ / h r)$} & \multirow{2}{*}{$\begin{array}{l}\text { Base } \\
\text { case }\end{array}$} & \multirow[b]{2}{*}{ EEOD } & \multirow[b]{2}{*}{ PCOD } & & & \\
\hline & $\begin{array}{l}\text { Base } \\
\text { case }\end{array}$ & EEOD & PCOD & $\begin{array}{l}\text { Base } \\
\text { case }\end{array}$ & EEOD & PCOD & $\begin{array}{l}\text { Base } \\
\text { case }\end{array}$ & EEOD & PCOD & & & & $\begin{array}{l}\text { Base } \\
\text { case }\end{array}$ & EEOD & PCOD \\
\hline $\begin{array}{c}\mathrm{HP} \\
\text { Evaporator }\end{array}$ & 14.640 & 15.580 & 14.200 & 0.16440 & 0.17080 & 0.13400 & 8.240 & 8.273 & 10.230 & 8.404 & 8.444 & 10.360 & 98.04 & 97.98 & 98.71 \\
\hline LP Turbine & 14.270 & 16.250 & 14.320 & 0.26730 & 0.30710 & 0.19280 & 22.250 & 23.550 & 22.250 & 22.520 & 23.860 & 22.440 & 98.81 & 98.71 & 99.14 \\
\hline Preheater 2 & 8.323 & 8.780 & 8.836 & 0.11000 & 011340 & 0.09258 & 7.208 & 7.260 & 10.270 & 7.318 & 7.373 & 10.360 & 98.50 & 98.46 & 99.11 \\
\hline HP Pump 2 & 1.884 & 1.928 & 2.567 & 0.02919 & 0.02927 & 0.03147 & 6.349 & 6.338 & 7.437 & 6.378 & 6.367 & 7.469 & 99.54 & 99.54 & 99.58 \\
\hline Preheater 1 & 12.590 & 14.370 & 7.501 & 0.18450 & 0.20600 & 0.08467 & 6.831 & 6.946 & 8.588 & 7.016 & 7.152 & 8.673 & 97.37 & 97.12 & 99.02 \\
\hline $\begin{array}{c}\text { LP } \\
\text { Evaporator }\end{array}$ & 11.470 & 11.840 & 9.752 & 0.12020 & 0.12120 & 0.08335 & 6.024 & 5.976 & 7.036 & 6.144 & 6.098 & 7.120 & 98.04 & 98.01 & 98.83 \\
\hline HP Turbine & 6.229 & 6.636 & 9.138 & 0.07441 & 0.07745 & 0.09285 & 14.940 & 15.470 & 18.400 & 15.010 & 15.540 & 18.500 & 99.50 & 99.50 & 99.50 \\
\hline LP Pump 1 & 1.637 & 1.700 & 1.478 & 0.03096 & 0.03242 & 0.02011 & 4.003 & 3.888 & 3.683 & 4.034 & 3.920 & 3.703 & 99.23 & 99.17 & 99.46 \\
\hline Superheater & 0.456 & 0.469 & 0.520 & 0.00534 & 0.00536 & 0.00518 & 3.963 & 3.956 & 3.881 & 3.968 & 3.962 & 3.886 & 99.87 & 99.86 & 99.87 \\
\hline Condenser & 39.110 & 24.910 & 35.070 & 0.32640 & 0.20960 & 0.25110 & 7.139 & 8.880 & 8.392 & 7.465 & 9.090 & 8.643 & 95.63 & 97.69 & 97.09 \\
\hline Total & 110.609 & 102.463 & 103.382 & 1.313 & 1.273 & 0.988 & 86.950 & 90.530 & 100.20 & 88.260 & 91.810 & 101.20 & 98.45 & 98.61 & 99.03 \\
\hline
\end{tabular}

$\dot{Z}+\dot{C}_{D}$, effort to select components with low capital investment cost and operating and maintenance cost might be employed.

\section{Conclusions}

This work investigates the thermodynamic, exergoeconomicand optimization of the dual-pressure organic Rankine cycle (DORC) for the utilization of medium temperature geothermal source for power production. Since several literatures [2] [11] have reported the advantages of DORC over the simple organic Rankine (SORC) in terms of first and second law thermodynamic performance, this study focuses on the exergoeconomic analysis and optimization of DORC to determine the exergy cost rates at each stream and obtain an optimized design for minimum product costs. This study is important considering the complex configuration of DORC and the potential high investment costs associated with it. The study conclusions reveals that the LP turbine have the highest value of $\dot{Z}+\dot{C}_{D}$, followed by HP turbine and HP evaporator, and from exergoeconomic viewpoint these components should receive more attention to achieve system improvement. The high values of the exergoeconomic factor, $f$, for these components indicate that the capital investment cost $\dot{Z}$ dominate the contribution of cost rate due to exergy destruction in the $\dot{Z}+\dot{C}_{D}$ parameter. Therefore, the use of cheaper components like HP evaporator, LP turbine and HP turbine will have remarkable improvement on the system cost effectiveness. Also, two optimization cases were performed on the DORC with regards to maximum exergy effi- 
ciency optimized design (EEOD) and minimum product cost optimized design (PCOD). The PCOD case proved to be the best with respect to both units cost of power produced and net power produced, with product unit cost of $17.4 \%$ and $14.64 \%$ lower than base case and EEOD case, respectively, and a net power output of $12.55 \%$ and $2.6 \%$ higher than the base case and EEOD, respectively.

It is observed that the condenser have the highest rate of exergy destroyed, $\dot{E}_{D}$ compared to the other components, which is due to exergy lost to cooling water in the condenser. To minimize this loses in the condenser, hence improve system performance, further investigations may be performed on how to utilize some energy in the LP turbine exit stream for absorption cooling or domestic water heating before entering the condenser.

\section{Acknowledgements}

The authors acknowledge the support of Department of Mechanical Engineering, Faculty of Engineering, Cross River University of Technology, Calabar, Nigeria.

\section{Conflicts of Interest}

The authors declare no conflicts of interest regarding the publication of this paper.

\section{References}

[1] Yang, M.H. and Yeh, R.H. (2015) Economic Performances Optimization of the Transcritical Rankine Cycle Systems in Geothermal Application. Energy Conversion and Management, 95, 20-31. https://doi.org/10.1016/j.enconman.2015.02.021

[2] Wang, M., Chen, Y., Liu, Q. and Zhao, Y. (2018) Thermodynamic and Thermo-Economic Analysis of Dual-Pressure and Single Pressure Evaporation Organic Rankine Cycles. Energy Conversion and Management, 177, 718-736. https://doi.org/10.1016/j.enconman.2018.10.017

[3] Li, J., Ge, Z., Duan, Y., Yang, Z. and Liu, Q. (2018) Parametric Optimization and Thermodynamic Performance Comparison of Single-Pressure and Dual-Pressure Evaporation Organic Rankine Cycles. Applied Energy, 217, 409-421. https://doi.org/10.1016/j.apenergy.2018.02.096

[4] Tchanche, B. F., Lambrinos, G., Frangoudakis, A. and Papadakis, G. (2011) Low-Grade Heat Conversion into Power Using Organic Rankine Cycles-A Review of Various Applications. Renewable and Sustainable Energy Reviews, 15, 3963-3979. https://doi.org/10.1016/j.rser.2011.07.024

[5] Braimakis, K. and Karellas, S. (2018) Energetic Optimization of Regenerative Organic Rankine Cycle (ORC) Configurations. Energy Conversion and Management, 159, 353-370. https://doi.org/10.1016/j.enconman.2017.12.093

[6] International Renewable Energy Agency (IRENA) (2017) Geothermal Power: Technology Brief (September). International Renewable Energy Agency, Abu Dhabi.

[7] Guzovi, Z., Rašković, P. and Blatarić, Z. (2014) The Comparison of a Basic and a Dual-Pressure ORC (Organic Rankine Cycle): Geothermal Power Plant Velika Ciglena Case Study. Energy, 76, 175-186. https://doi.org/10.1016/j.energy.2014.06.005 
[8] Ziviani, D., Beyene, A. and Venturini, M. (2014) Advances and Challenges in ORC Systems Modeling for Low Grade Thermal Energy Recovery. Applied Energy, 121, 79-95. https://doi.org/10.1016/j.apenergy.2014.01.074

[9] Lecompte, S., Huisseune, H., Van Den Broek, M., Vanslambrouck, B. and De Paepe, M. (2015) Review of Organic Rankine Cycle (ORC) Architectures for Waste Heat Recovery. Renewable and Sustainable Energy Reviews, 47, 448-461. https://doi.org/10.1016/j.rser.2015.03.089

[10] Li, T., Zhang, Z., Lu, J., Yang, J. and Hu, Y. (2015) Two-Stage Evaporation Strategy to Improve System Performance for Organic Rankine Cycle. Applied Energy, 150, 323-334. https://doi.org/10.1016/j.apenergy.2015.04.016

[11] Shokati, N., Ranjbar, F. and Yari, M. (2015) Exergoeconomic Analysis and Optimization of Basic, Dual-Pressure and Dual-Fluid ORCs and Kalina Geothermal Power Plants : A Comparative Study. Renewable Energy, 83, 527-542.

https://doi.org/10.1016/j.renene.2015.04.069

[12] Thierry, D.M., Flores-Tlacuahuac, A. and Grossmann, I.E. (2016) Simultaneous Optimal Design of Multi-Stage Organic Rankine Cycles and Working Fluid Mixtures for Low-Temperature Heat Sources. Computers and Chemical Engineering, 89, 106-126. https://doi.org/10.1016/j.compchemeng.2016.03.005

[13] Manente, G., Lazzaretto, A. and Bonamico, E. (2017) Design Guidelines for the Choice between Single and Dual Pressure Layouts in Organic Rankine Cycle (ORC) Systems. Energy, 123, 413-431. https://doi.org/10.1016/j.energy.2017.01.151

[14] Sadeghi, M., Nemati, A. and Yari, M. (2016) Thermodynamic Analysis and Multi-Objective Optimization of Various ORC (Organic Rankine Cycle) Configurations Using Zeotropic Mixtures. Energy, 109, 791-802.

https://doi.org/10.1016/j.energy.2016.05.022

[15] Li, J., Ge, Z., Liu, Q., Duan, Y. and Yang, Z. (2018) 'Thermo-Economic Performance Analyses and Comparison of Two Turbine Layouts for Organic Rankine Cycles with Dual-Pressure Evaporation. Energy Conversion and Management, 164, 603-614. https://doi.org/10.1016/j.enconman.2018.03.029

[16] Klein, S.A. (2020) Engineering Equation Solver. F-Chart Software, Madison.

[17] Bejan, A., Tsatsaronis, G. and Moran, M. (1996) Thermal Design \& Optimization. John Wiley \& Sons Inc., New York.

[18] Ahmadzadeh, A., Reza, M. and Sedaghat, A. (2017) Thermal and Exergoeconomic Analysis of a Novel Solar Driven Combined Power and Ejector Refrigeration (CPER) System. International Journal of Refrigeration, 83, 143-156. https://doi.org/10.1016/j.ijrefrig.2017.07.015

[19] Manente, G., Lazzaretto, A. and Bonamico, E. (2017) Design Guidelines for the Choice between Single and Dual Pressure Layouts in Organic Rankine Cycle (ORC) Systems. Energy, 123, 413-431. https://doi.org/10.1016/j.energy.2017.01.151

[20] Kazemi, N. and Samadi, F. (2016) Thermodynamic, Economic and Thermo-Economic Optimization of a New Proposed Organic Rankine Cycle for Energy Production from Geothermal Resources. Energy Conversion and Management, 121, 391-401. https://doi.org/10.1016/j.enconman.2016.05.046

[21] Cayer, E., Galanis, N. and Nesreddine, H. (2010) Parametric Study and Optimization of a Transcritical Power Cycle Using a Low Temperature Source. Applied Energy, 87, 1346-1357. https://doi.org/10.1016/j.apenergy.2009.08.031 


\section{Appendix A: Equipment Cost $\left(\dot{Z}_{J}\right)$ Calculation}

The equations for calculating the equipment purchase cost for the turbine, pumps and heat exchangers are expressed as follows [1] [21]:

$$
\begin{gathered}
Z_{\text {turb }}=C_{P, \text { turb }}\left(F_{M, \text { turb }} F_{P, \text { turb }}\right) \\
Z_{\text {pump }}=C_{P, \text { pump }}\left(B_{1, \text { pump }}+B_{2, \text { pump }} F_{M, \text { pump }} F_{P, \text { pump }}\right) \\
Z_{H X}=C_{P, H X}\left(B_{1, H X}+B_{2, H X} F_{M, H X} F_{P, H X}\right)
\end{gathered}
$$

where $C_{P}$ refers to component bare module cost and can be calculated as follows:

$$
\log C_{P, x}=K_{1, x}+K_{2, x} \log Y+K_{3, x}\left(\log Y^{2}\right)
$$

where $Y$ in Equation (A.4) indicates the capacity of the turbine and pump, or the area in the case of the heat exchanger. $K_{1}, K_{2}$ and $K_{3}$ are coefficients of equipment cost given in Table A1. $F_{M}$ is the material factor, and $B_{1}$ and $B_{2}$ are constants given in Table A1. $F_{P}$ is the pressure factor and can be obtained as follows:

$$
\log F_{P, x}=C_{1, x}+C_{2, x} \log (10 P-1)+C_{3, x}(\log (10 P-1))^{2}
$$

$C_{1}, C_{2}$ and $C_{3}$ are constants given in Table A1. The Marshall and Swift equipment cost indices [21] is utilized to convert Equations (A.1)-(A.3) from reference year to present year (2021).

$$
C_{2021}^{*}=C_{\text {original cost }} \frac{C I_{M . S}^{2021}}{C I_{M . S}^{\text {reference year }}}
$$

The LMTD method has been adopted in the present study to calculate the heat exchange area. The heat transfer rate in heat exchanger can be expressed as [1]:

$$
Q=U_{k} A_{k} \Delta T_{\text {mean }}
$$

Table A1. Equipment cost parameters [21].

\begin{tabular}{ccccccccccc}
\hline$X$ & $Y$ & $K_{1}$ & $K_{2}$ & $K_{3}$ & $B_{1}$ & $B_{2}$ & $C_{1}$ & $C_{2}$ & $C_{3}$ & $F_{M}$ \\
\hline Turbine & $\dot{W}_{\text {turb }}$ & 2.2476 & 1.4965 & -0.1618 & 0 & 1 & 0 & 0 & 0 & 3.4 \\
Pump & $\dot{W}_{\text {pump }}$ & 3.3892 & 0.0536 & 0.1538 & 1.89 & 1.35 & -0.3935 & 0.3957 & -0.0023 & 1.6 \\
$\begin{array}{c}\text { Heat } \\
\text { exchanger }\end{array}$ & $A_{H X}$ & 4.3247 & -0.3030 & 0.1634 & 1.63 & 1.66 & 0.0388 & -0.1127 & 0.0818 & 1 \\
\hline
\end{tabular}

Table A2. Approximate values of overall heat transfer coefficient from several heat exchangers.

\begin{tabular}{cc}
\hline Components & Overall heat transfer coefficient, $U_{k}\left(\mathrm{~kW} /\left(\mathrm{m}^{2} \mathrm{~K}\right)\right)$ \\
\hline Evaporator & 0.9 \\
Condenser & 1.1 \\
Heat exchanger & 1.0 \\
\hline
\end{tabular}


where $\Delta T_{\text {mean }}$ is the logarithmic mean temperature difference between the working fluid and the coolant, and $U_{k}$ is the overall heat transfer coefficient given in Table A2. 